\title{
MANEJO DA MICRO BACIA DO LAJEADO PARDO
}

\author{
L. G. RITTER ${ }^{*}$, V. D. RENZ, G. GARLET, P. CHAGAS, M. A. MANCUSO, A. HAAS e S. R. CONCEIÇÃO \\ Universidade Federal de Santa Maria \\ lucianaritter@yahoo.com*
}

Artigo submetido em setembro/2013 e aceito em novembro/2015

DOI: $10.15628 /$ holos.2015.1685

\section{RESUMO}

A bacia hidrográfica é considerada a unidade geográfica ideal para o planejamento e zoneamentos ambientais, possibilitando uma abordagem holística e participativa envolvendo estudos interdisciplinares para o estabelecimento de formas de desenvolvimento sustentável inerentes ao local ou região onde foram implementados. A agricultura e pecuária são áreas que necessitam de grandes áreas para a produção, ocasionando o desmatamento e degradação do ambiente. O objetivo do presente trabalho consiste em analisar os impactos ambientais causados na Micro Bacia Lajeado Pardo que abastece a cidade de Frederico Westphalen e indicar possíveis soluções para os problemas. $O$ estudo consiste na realização de visitas a campo para posterior elaboração de diagnóstico. Ao longo do percurso do Lajeado Pardo a área apresenta problemas como o solo descoberto, falta de vegetação marginal, curso d'agua interrompido, construções instaladas em zonas de drenagem, despejo inadequado de efluentes no curso, bem como disposição inadequada de resíduos. Para evitar ocorrências de inundações, desmoronamentos entre outros, deve-se realizar o planejamento e gestão de futuras instalações nas proximidades do curso d'água. A promoção do manejo integrado de bacias hidrográficas auxilia na gestão sustentável do ambiente, garantindo assim a sua integridade e os usos futuros.

PALAVRAS-CHAVE: planejamento, impactos ambientais, gestão sustentável.

\section{MANAGEMENT OF MICRO BASIN LAJEADO PARDO}

\section{ABSTRACT}

The watershed is considered the geographical unit ideal for environmental planning and zoning, enabling a holistic and participatory approach involving interdisciplinary studies for the establishment of sustainable forms of development inherent in the place or region where they were implemented. Agriculture and livestock are areas that require large areas for production, causing deforestation and environmental degradation. The objective of this study is to analyze the environmental impacts in Micro Paved Pardo basin that supplies the city of Fredericksburg and indicate possible solutions to problems. The study involves carrying out field visits for
\end{abstract}

further elaboration of diagnosis. Along the route of the Paved Pardo area presents problems such as bare soil, lack of riparian vegetation, watercourse water stopped, buildings installed in drainage areas, inadequate disposal of waste in the course, as well as improper disposal of waste. To prevent occurrences of floods, landslides among others, should carry out the planning and management of future facilities nearby watercourse. The promotion of integrated management of watersheds assists in the sustainable management of the environment, thus ensuring its integrity and future uses.

KEYWORDS: planning, environmental impacts, sustainable management. 


\section{INTRODUÇÃO}

De acordo com a Lei no 6.938, da Política Nacional de Meio Ambiente - PNMA, a bacia hidrográfica é considerada a unidade geográfica ideal para o planejamento e zoneamentos ambientais, usando como unidades de planejamento, pois as bacias possuem características ecológicas, geomorfológicas e sociais integradoras, o que possibilita uma abordagem holística e participativa envolvendo estudos interdisciplinares para o estabelecimento de formas de desenvolvimento sustentável inerentes ao local ou região onde foram implementados (Attanasio, 2004).

Para manter o abastecimento de água de boa qualidade Donadi et al. (2005), destaca a importância das bacias com cobertura de floresta natural, devido a vegetação promover a proteção contra a erosão do solo, a sedimentação e a lixiviação excessiva de nutrientes. Por outro lado, as práticas que se seguem após a retirada das árvores tendem a produzir intensas e prolongadas degradação da qualidade da água.

De acordo com Carvalho (2000), tanto a agricultura como a pecuária são atividades econômicas, que necessitam de grandes áreas, onde o desmatamento é a primeira consequência negativa para o ambiente, deixando o solo exposto à lixiviação, favorecendo o carregamento de sedimentos para os rios e lagos, podendo acarretar no aumento do uso de fertilizantes, desequilibrando o conteúdo de nutrientes do solo e facilitando a contaminação química do ambiente.

Os fenômenos acorridos dentro de uma bacia, sejam eles de origem natural ou antrópica, interferem na dinâmica sistêmica, na quantidade e qualidade dos cursos de água e as medidas de algumas de suas variáveis (solo, clima, vegetação, relevo, entre outros) permitem compreender a soma desses fenômenos (Corseuil, 2006).

E, segundo Rocha (1997), o estudo e o manejo integrado das bacias hidrográficas são os únicos caminhos a serem seguidos para o diagnóstico bem como a recuperação ambiental dessas unidades, conduzindo ao equilíbrio dos ecossistemas ali existentes.

Sendo assim, este estudo visa analisar os impactos ambientais causados na Micro Bacia Lajeado Pardo que abastece a cidade de Frederico Westphalen e indicar possíveis soluções para os problemas.

\section{METODOLOGIA}

Durante as visitas na área de estudo, analisou-se, através de observação, os impactos visuais causados a Micro Bacia Lajeado Pardo, bem como uso e ocupação do solo, áreas de APP, vegetação, localização do curso d'água.

Após analise geral da área em estudo, e posterior embasamento teórico foi elaborado um diagnostico com possíveis soluções a cerca dos problemas encontrados. 


\section{1 Área de estudo}

O município de Frederico Westphalen está localizado na região Norte do Estado de Rio Grande do Sul, conforme figura 1. A uma latitude 2721'33" sul e a uma longitude 5323'40" oeste, estando a uma altitude de 566 metros. Possui uma população de 28.848 habitantes (IBGE, 2010) e uma área de $264,53 \mathrm{~km} 2$.

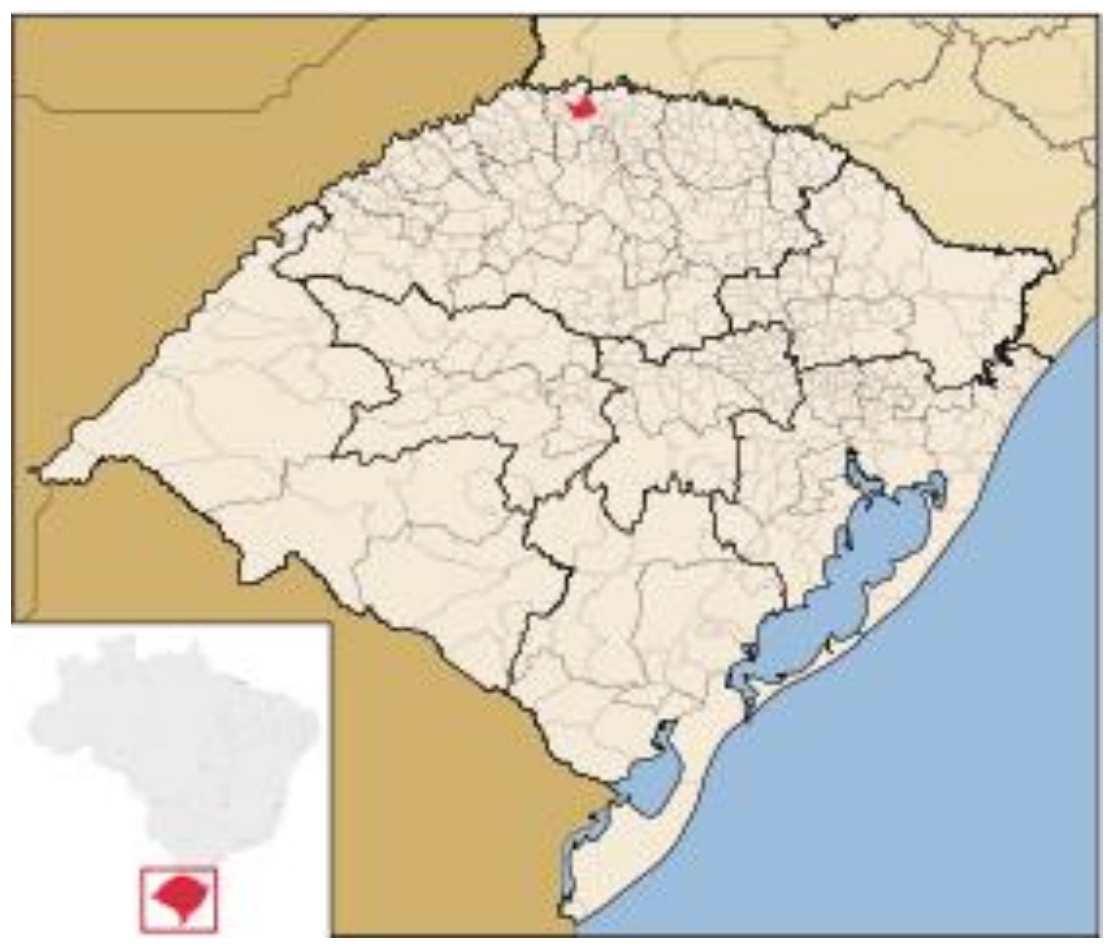

Figura 1: Localização do município de Frederico Westphalen Fonte: http://pt.wikipedia.org/wiki/Frederico_Westphalen

O clima da cidade de Frederico Westphalen é do tipo Cfb segundo a classificação de Köppen com temperatura média anual em torno de $18^{\circ} \mathrm{C}$, podendo atingir máximas de $41^{\circ} \mathrm{C}$ no verão e mínimas inferiores a 0 ㅇ C no inverno. A precipitação média anual varia entre 1.800 e 2.100 mm, bem distribuídos durante o ano (Bernardi et al., 2008).

A Bacia Hidrográfica Rio da Várzea situa-se ao norte do Estado do Rio Grande do Sul, entre as coordenadas geográficas $27^{\circ} 00^{\prime}$ a $28^{\circ} 20^{\prime}$ de latitude Sul e $52^{\circ} 30^{\prime}$ a $53^{\circ} 50^{\prime}$ de longitude Oeste. Abrange a Província Geomorfológica Planalto Meridional. Possui uma área de 9.463,46 Km², abrangendo 55 municípios. As atividades econômicas são predominantemente agrícolas, com lavouras de soja, trigo e milho, bem como avicultura e suinocultura. Destaca-se, ainda, o potencial hidrelétrico desta bacia e as atividades de mineração (extração de pedras preciosas e semipreciosas, como ágata, ametista, etc.) (Prefeitura Municipal de Frederico Westphalen/RS, 2011).

A Micro Bacia Lajeado do Pardo tem sua nascente nas coordenadas latitude $27025^{\prime}$ '43"S; longitude 5343'25" W, conforme figura 2, e uma altitude média de $488 \mathrm{~m}$ e possui uma área de 29386 ha, cujo comprimento da rede hidrográfica é de $373436 \mathrm{~m}$. O Rio Lajeado Pardo está localizado do lado esquerdo da BR 386, próximo ao Km 40 em Frederico Westphalen, na área em que se localiza o campus de Frederico Westphalen da Universidade Federal de Santa Maria. 


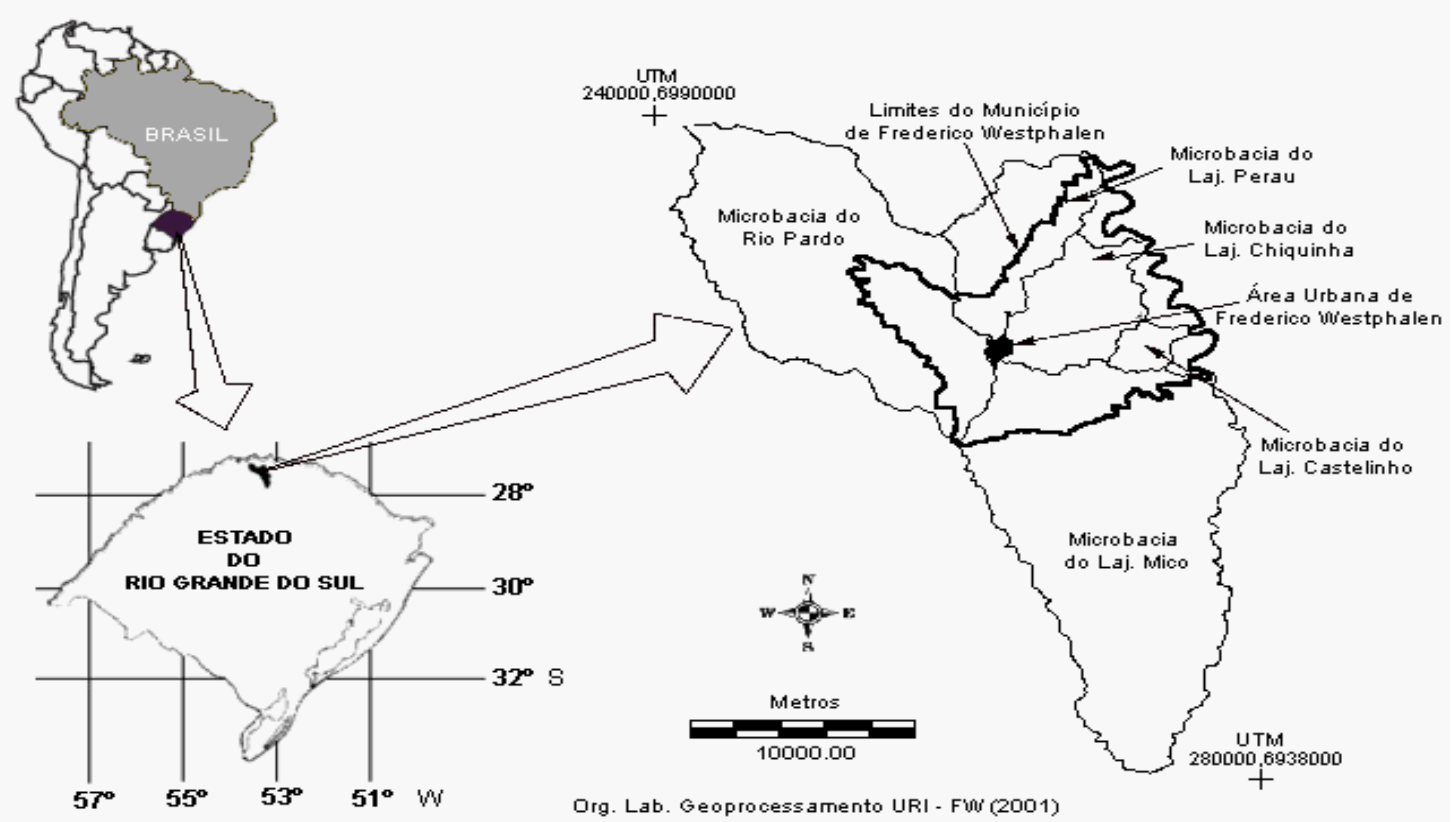

Figura 2: Localização da Micro Bacia do Lajeado Pardo.

A principal atividade econômica da região é desenvolvida no meio rural através da agricultura, pois segundo Borghetti et. tal., (2008) é uma região caracteriza-se por terras férteis e solos com altos índices de produtividade. As atividades agrícolas envolvem no processo produtivo substâncias químicas como agrotóxicos (herbicidas, inseticidas, fungicidas), fertilizantes e a geração de resíduos e poluentes, que em última análise, provocam a contaminação do solo e água.

\section{RESULTADOS E DISCUSSÕES}

\subsection{Diagnóstico}

Na zona mais elevada, onde localiza-se a nascente do Lajeado Pardo há predominância de vegetação para proteção do manancial (Figura 3).

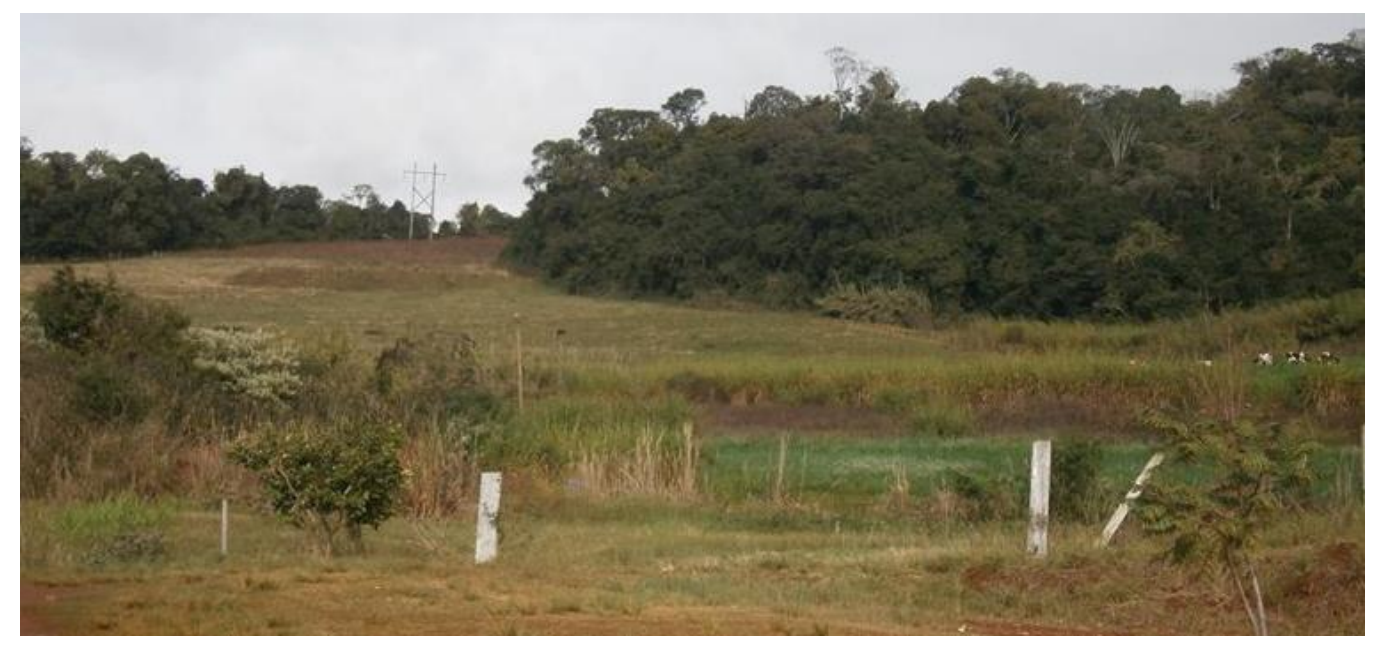

Figura 3: Nascente do Lajeado Pardo, Frederico Westphalen, RS

Fonte: Autores, 2013. 
Ao longo do seu percurso, a área apresenta problemas como o solo descoberto, falta de vegetação marginal, curso d'agua interrompido, construções instaladas em zonas de drenagem, despejo inadequado de efluentes no curso, bem como disposição inadequada de resíduos.

O processo de desmatamento da mata ciliar buscando obter novas áreas para implantação de cultivos agrícolas ocasiona solo descobertos que são susceptíveis a processos erosivos, conforme figura 4.

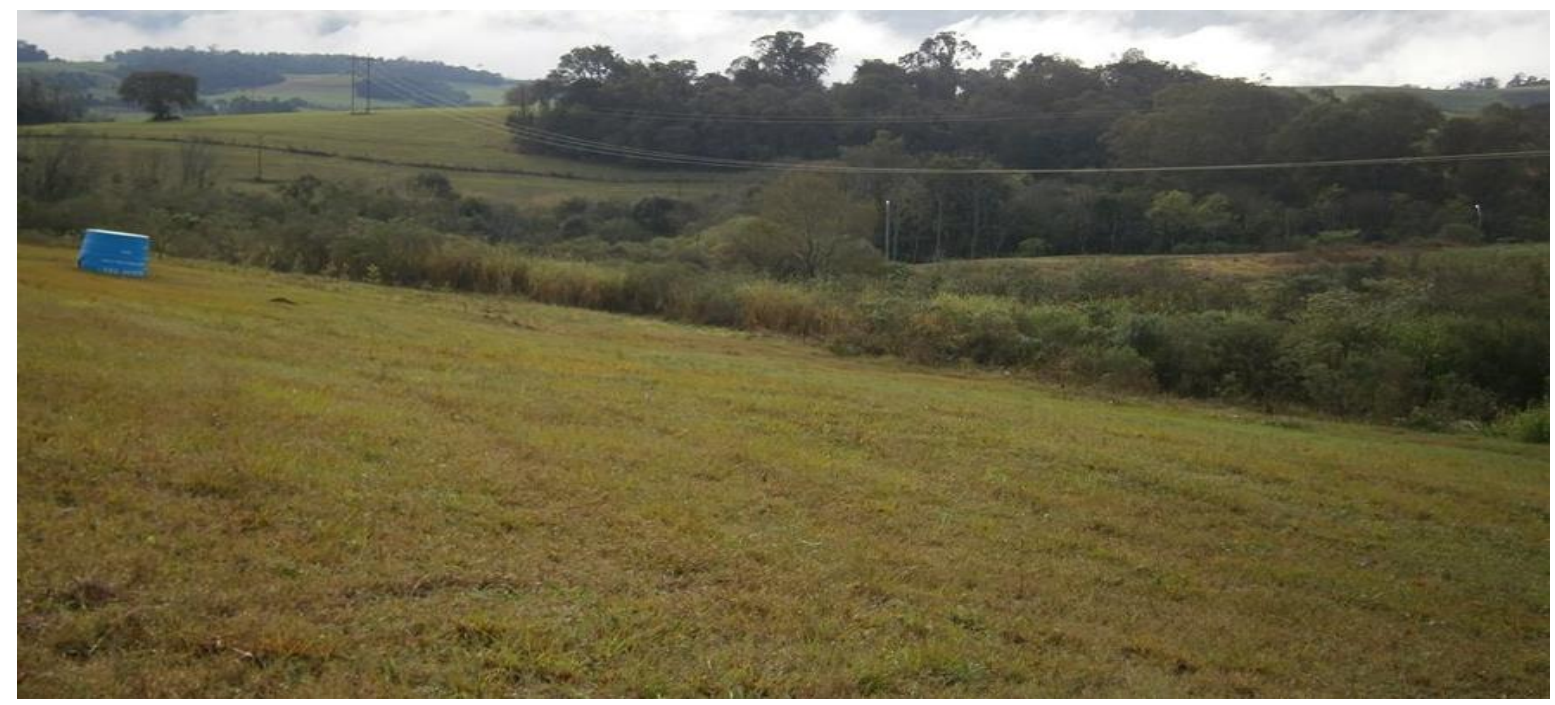

Figura 4: Solos susceptíveis ao processo erosivo Fonte: Autores, 2013

A fim de possibilitar a instalação de viveiros da Universidade, realizou-se a interrupção do curso d'água, através do desvio do mesmo por trás das estufas e da construção de duas estruturas de represamento (Figura 5). Esta estrutura está localizada em zona de inundação que apresenta uma vegetação característica, causando alteração da dinâmica hídrica.

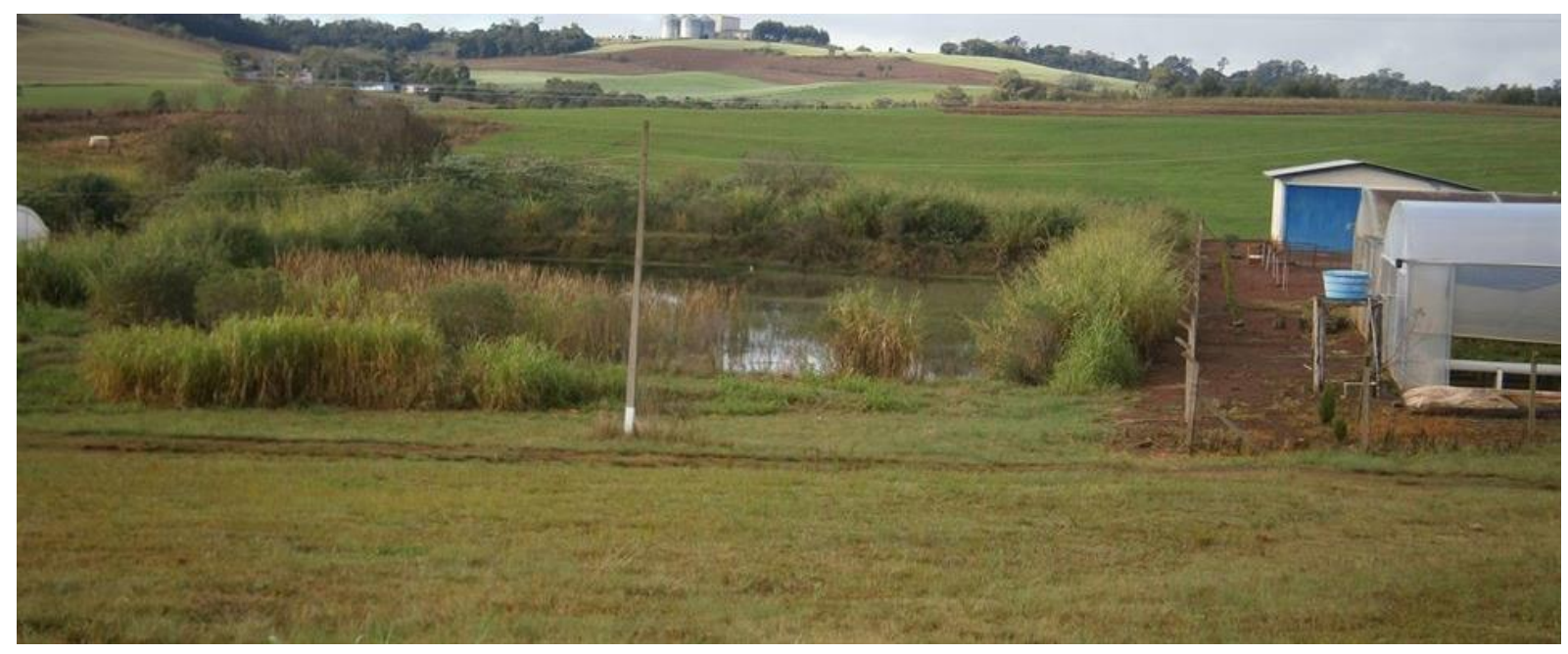

Figura 5: Modificações no curso d'água

Fonte: Autores, 2013

Ao longo do percurso foram encontrados locais com disposição de resíduos bem como despejo inadequado de efluentes no curso d'água (Figura 6). 


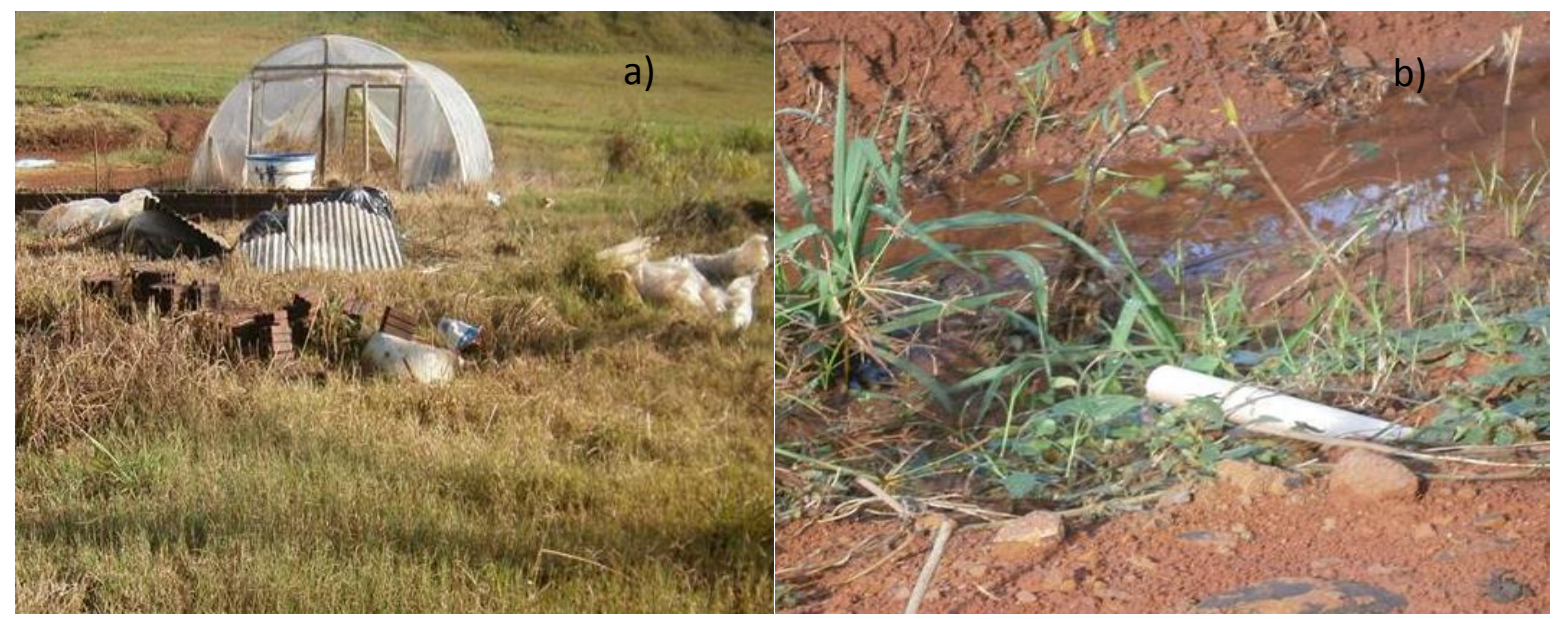

Figura 6: Manejo inadequado do curso d'água. a) Disposição inadequada de resíduos; b) Despejo inadequado de efluentes.

Fonte: Autores, 2013

Nesta região também existem poços de captação de águas subterrâneas, os quais estão localizados próximos ao curso d'água e se os mesmos estiverem contaminados, possivelmente ocasionarão a contaminação aos poços.

\subsection{Alternativas propostas}

Para evitar ocorrências de inundações, desmoronamentos entre outros, deve-se realizar o planejamento e gestão de futuras instalações nas proximidades do curso d'água.

O gerenciamento do uso e ocupação do solo, com a aplicação de métodos de cultivo adequados, minimiza os processos erosivos e evita o carreamento de poluentes para o curso d'água.

Deve-se também recuperar a mata ciliar respeitando os limites estabelecidos pela legislação vigente, garantindo assim a melhor qualidade da água.

Torna-se importante também realizar a implantação de programas de monitoramento da qualidade da água, auxiliando no diagnóstico de possíveis contaminações.

\subsection{Legislação}

A RESOLUÇÃO CONAMA № 357, DE 17 DE MARÇO DE 2005 dispõe sobre a classificação dos corpos de água e diretrizes ambientais para o seu enquadramento, bem como estabelece as condições e os padrões de lançamento de efluentes, e dá outras providências.

No seu capítulo IV, trata das condições e padrões de lançamento de efluentes, e segundo o Art. 24"Os efluentes de qualquer fonte poluidora somente poderão ser lançados, direta ou indiretamente, nos corpos de água, após o devido tratamento e desde que obedeçam às condições, padrões e exigências dispostos nesta Resolução e em outras normas aplicáveis".

Já no Art. 34 desta resolução, inciso 5o são apresentados os padrões de lançamentos de efluentes (Figura 7). 


\begin{tabular}{|c|c|}
\hline \multirow{2}{*}{\multicolumn{2}{|c|}{ TABELA X - LANCAMENTO DE EFLUENTES }} \\
\hline & \\
\hline PARAMETROS INORGANICOS & VALOR MAXXIMO \\
\hline Arsênio total & $0,5 \mathrm{mg} / \mathrm{L} \mathrm{As}$ \\
\hline Bário total & $5.0 \mathrm{mg} / \mathrm{L} \mathrm{Ba}$ \\
\hline Boro total & $5,0 \mathrm{mg} / \mathrm{L} \mathrm{B}$ \\
\hline Cádmio total & $0,2 \mathrm{mg} / \mathrm{L} \mathrm{Cd}$ \\
\hline Chumbo total & $0,5 \mathrm{mg} / \mathrm{L} \mathrm{Pb}$ \\
\hline Cianeto total & $0.2 \mathrm{mg} / \mathrm{L} \mathrm{CN}$ \\
\hline Cobre dissolvido & $1.0 \mathrm{mg} / \mathrm{L} \mathrm{Cu}$ \\
\hline Cromo total & $0,5 \mathrm{mg} / \mathrm{L} \mathrm{Cr}$ \\
\hline Estanho total & $4.0 \mathrm{mg} / \mathrm{L} \mathrm{Sn}$ \\
\hline Ferro dissolvido & $15,0 \mathrm{mg} / \mathrm{L} \mathrm{Fe}$ \\
\hline Fluoreto total & $10,0 \mathrm{mg} / \mathrm{L} \mathrm{F}$ \\
\hline Manganês dissolvido & $1,0 \mathrm{mg} / \mathrm{L} \mathrm{Mn}$ \\
\hline Mercúrio total & $0,01 \mathrm{mg} / \mathrm{L} \mathrm{Hg}$ \\
\hline Niquel total & $2,0 \mathrm{mg} / \mathrm{L} \mathrm{Ni}$ \\
\hline Nitrogênio amoniacal total & $20,0 \mathrm{mg} / \mathrm{L} \mathrm{N}$ \\
\hline Prata total & $0.1 \mathrm{mg} / \mathrm{L} \mathrm{Ag}$ \\
\hline Selênio total & $0,30 \mathrm{mg} / \mathrm{L} \mathrm{Se}$ \\
\hline Sulfeto & $1.0 \mathrm{mg} / \mathrm{L} \mathrm{S}$ \\
\hline Zinco total & $5,0 \mathrm{mg} / \mathrm{L} \mathrm{Zn}$ \\
\hline PARAMETROS ORGANICOS & VALOR MAXIMO \\
\hline Clorofórmio & $1,0 \mathrm{mg} / \mathrm{L}$ \\
\hline Dicloroeteno & $1,0 \mathrm{mg} / \mathrm{L}$ \\
\hline $\begin{array}{l}\text { Fenóis totais (substâncias que reagem com 4- } \\
\text { aminoantipirina) }\end{array}$ & $0,5 \mathrm{mg} / \mathrm{L} \mathrm{C} \mathrm{CH}_{5} \mathrm{OH}$ \\
\hline Tetracloreto de Carbono & $1,0 \mathrm{mg} / \mathrm{L}$ \\
\hline Tricloroeteno & $1,0 \mathrm{mg} / \mathrm{L}$ \\
\hline
\end{tabular}

Figura 7: Padrões de lançamento de efluentes segundo a Resolução CONAMA №357.

Fonte: BRASIL, 2005

A Lei № 12.651, DE 25 DE MAIO DE 2012, que dispõe sobre a proteção da vegetação nativa, em seu artigo 40 traz a Delimitação das Áreas de Preservação Permanente, sendo aplicáveis ao estudo os seguintes aspectos:

I - as faixas marginais de qualquer curso d'água natural perene e intermitente, excluídos os efêmeros, desde a borda da calha do leito regular, em largura mínima de:

a) 30 (trinta) metros, para os cursos d'água de menos de 10 (dez) metros de largura.

IV - as áreas no entorno das nascentes e dos olhos d'água perenes, qualquer que seja sua situação topográfica, no raio mínimo de 50 (cinquenta) metros.

Outro instrumento aplicável ao estudo é a Lei № 12.305, DE 2 DE AGOSTO DE 2010, que institui a Política Nacional de Resíduos Sólidos. O capítulo VI da referida lei estabelece as proibições, e em seu artigo 47 estabelece que é proibido o lançamento in natura a céu aberto, excetuados os resíduos de mineração.

\section{CONCLUSÃO}

O modelo de civilização geradora da crise ambiental pela qual passamos é o resultado da relação desmistificada e utilitarista do homem com a natureza, onde o ser humano está promovendo a degradação do ambiente, o que afeta a sua própria saúde.

A ausência de vegetação ao longo de toda a extensão do percurso do lajeado, além de estar em desacordo com as exigências previstas em lei, diminui a preservação do local e a manutenção da biodiversidade, afetando também as taxas de infiltração no solo e o escoamento superficial. 
A promoção do manejo integrado de bacias hidrográficas auxilia na gestão sustentável do ambiente, garantindo assim a sua integridade e os usos futuros.

\section{REFERÊNCIAS}

1. ATTANASIO, C. M. Planos de manejo integrado em microbacias hidrográficas com uso agrícola: uma abordagem hidrológica na busca da sustentabilidade. Piracicaba. 2004. 2004. Tese (Doutorado em Recursos Florestais) - Escola Superior de Agricultura "Luiz de Queiroz" Universidade de São Paulo, 2004.

2. BERNARDI, I. P.; TEIXEIRA, E. M.; JACOMASSA, F. A. F. Registros relevantes da avifauna do Alto Uruguai, Rio Grande do Sul, Brasil. BIOCIÊNCIAS, Porto Alegre, v. 16, n. 2, p. 134-137, jul. 2008.

3. BORGHETTI, N. R. B., BORGHETTI, J. R., ROSA FILHO, E. F. da. Aqüífero Guaraní. Edição on-line 214 Páginas. Disponível em: <http://www.oaquiferoguarani.com.br/index_02.htm>.

4. BRASIL. Ministério do Meio Ambiente. Conselho Nacional do Meio Ambiente. Resolução CONAMA no 357, de 17 de março de 2005. Brasília, 2005. Disponível em: < http://www.mma.gov.br/port/conama/res/res05/res35705.pdf>. Acesso em 13 jun. 2013.

5. CARVALHO, N. de O. Hidrossedimentologia Prática. Rio de Janeiro: Companhia de Pesquisa em Recursos Minerais, 372p. 2000.

6. CORSEUIL, C. W. Técnicas de geoprocessamento e de análise de multicritérios na adequação de uso das terras. Botucatu, 2006. 101 f. Tese (Doutorado em Agronomia/Energia na Agricultura) - Faculdade de Ciências Agronômicas, Universidade Estadual Paulista, 2006.

7. DONADIO, N. M. M., et al. Qualidade da água de nascentes com diferentes usos do solo na bacia hidrográfica do córrego rico. São Paulo, Brasil. Engenharia Agrícola. Jaboticabal, v. 25, n. 1, p. 115-125, jan-abr. 2005.

8. PREFEITURA MUNICIPAL DE FREDERICO WESTPHALEN. Grupo de Trabalho PMSB-FW. Plano Municipal de Saneamento Básico de Frederico Westphalen/RS. Frederico Westphalen, 2011.

9. ROCHA FILHO, J.; PRIMAVESI, O. Aplicação do SIG-IDRISI para Estudo e Classificação das Áreas de Proteção dos Recursos Naturais na Fazenda Canchim (EMBRAPA São Carlos - SP). In: II Simpósio de Usuários IDRISI, II., 1997, Campinas. Caderno de Resumos... Campinas: UNICAMP/FEAGRI. FPE/Faculdade de Agronomia "Manoel Carlos Gonçalves" e EMBRAPA/CNPTIA, p. 5-7. 1997. 